УДК 616.89-02-036:616-002.2:612.017

Для цитирования: Зозуля С.А., Отман И.Н., Олейчик И.В., Аниховская И.А., Яковлев М.Ю., Клюшник Т.П. Сопряженность процессов системного воспаления и системной эндотоксинемии при эндогенных психозах. Сибирский вестник психиатрии и наркологии. 2020; 3 (108): 17-27. https://doi.org/10.26617/1810-3111-20203(108)-17-27

\title{
Сопряженность процессов системного воспаления и системной эндотоксинемии при эндогенных психозах \\ Зозуля С.А. ${ }^{1}$, Отман И.н. ${ }^{1}$,Олейчик И.В. ${ }^{1}$, Аниховская И.А.. ${ }^{2,}$, Яковлев М.ю., 3, ${ }^{2,}$ Клюшник Т.П.'
}

${ }^{1}$ ФГБНУ «Научный центр психического здоровья»

Россия, 115522, Москва, Каширское шоссе, д. 34

2 ФГБНУ «Научно-исследовательский институт общей патологии и патофизиологии»

Россия, 125315, Москва, ул. Балтийская, д. 8

${ }^{3}$ ООО «Клинико-диагностическое общество»

Россия, 127083, Москва, ул. Нижняя Масловка, д. 19

${ }^{4}$ ФГБОУ ВО «Российский национальный исследовательский медицинский университет имени Н.И. Пирогова» Россия, 117997, Москва, ул. Островитянова, д. 1

\section{PEЗЮME}

Цель исследования: анализ сопряженности процессов системного воспаления и системной эндотоксинемии во взаимосвязи с клиническими особенностями пациентов с эндогенными психозами (ЭГП) до и после психофармакотерапии. Материал и методы: в исследование включены 25 пациентов с шизофренией (F20.0 (0-1) по МКБ-10) и шизоаффективным психозом (F25.0), обследованных при поступлении в стационар (в остром психотическом состоянии) и перед выпиской (после проведенной фармакотерапии). Контрольную группу составили 25 здоровых человек. В крови обследованных определяли маркеры системного воспаления (активность лейкоцитарной эластазы - ЛЭ), функциональную активность $\alpha 1$-протеиназного ингибитора ( $\alpha 1$ ПИ), уровень антител (АТ) к S100B и ОБМ, а также показатели системной эндотоксинемии (СЭЕ) (концентрацию эндотоксина, уровень и соотношение антиэндотоксиновых АТ). Результаты: в остром психотическом состоянии (до лечения) выявлено повышение активности ЛЭ и $\alpha 1-П И$ в группе пациентов по сравнению с контрольной группой (p<0,001). Уровень AT к S100B и ОБМ, а также показатели СЭЕ не отличались от значений в контрольной группе (p>0,05), однако наблюдалась их значительная вариабельность. При обследовании после проведенной терапии в структуре выборки было выделено два кластера. В качестве кластеризующих признаков использовали маркеры системного воспаления, уровень которых связан с активностью патологического процесса в мозге. У пациентов первого кластера (56\%) наблюдались хороший клинический эффект и относительная нормализация всех показателей. У пациентов второго кластера (44\%), несмотря на улучшение клинического состояния, обнаружены повышение активности ЛЭ и $\alpha 1-П И$, активация аутоиммунных реакций к нейроантигенам, а также лабораторные признаки эндотоксиновой агрессии (ЭА): высокая концентрация ЭТ в плазме крови на фоне дефицита антиэндотоксиновых АТ к гидрофобной части его молекулы ( $<<0,01)$. Заключение. Анализ сопряженности изучаемых систем во взаимосвязи с клиническим состоянием пациентов с ЭГП до и после фармакотерапии позволяет предположить участие ЭА в утяжелении психопатологической симптоматики у данной категории пациентов.

Ключевые слова: эндогенные психозы, маркеры воспаления, системная эндотоксинемия, аутоантитела к нейроантигенам, эндотоксиновая агрессия.

\section{ВВЕДЕНИЕ}

Шизофрения - хроническое прогредиентное заболевание со средней распространенностью среди населения 4,0 на 1000 человек, характеризующееся многообразными нарушениями поведенческих и когнитивных функций [1]. Патогенез шизофрении регулируется сложным взаимодействием генетических и средовых (эпигенетических) факторов, среди которых особое место принадлежит микробиоте кишечника [2].
Клинические и экспериментальные исследования последних лет показали, что изменение состава кишечной микробиоты, а также дисбаланс её метаболитов связаны с развитием шизофрении, однако накопленные знания о молекулярных механизмах, лежащих в основе этой взаимосвязи, остаются очень неполными [3].

Показано, что микробиота может модулировать функцию ЦНС через ось «мозг - кишечник» посредством различных механизмов, включая 
нейротрансмиссию, передачу сигналов через блуждающий нерв, гипоталамус-гипофизарнонадпочечниковую ось, а также путём активации иммунной системы [4]. Высказано предположение, что повышенная микробная нагрузка может модулировать развитие нейровоспаления - одного из ключевых механизмов развития шизофрении, что приводит к повреждению нейронов, синапсов, нарушению связей между различными областями мозга, усугубляя течение шизофренического процесса [5].

Одним из ведущих факторов, инициирующих активацию воспалительных реакций, является избыток в кровотоке кишечного эндотоксина (ЭТ) или бактериального липополисахарида (ЛПС) термостабильного компонента наружной части клеточной мембраны всех грамотрицательных микроорганизмов [6]. Показано, что ЭТ оказывает повреждающее действие на эндотелий сосудов гематоэнцефалического барьера (ГЭБ), вызывает индукцию синтеза провоспалительных цитокинов, следствием чего является активация микроглии и модификация активности иммунных процессов в мозге и на периферии. На клиническом уровне это находит проявление в виде различных психопатологических нарушений [7]. О возможной роли ЛПС в развитии эндогенных психозов (ЭГП) могут свидетельствовать корреляции связанных с ним маркеров бактериальной транслокации, таких как SCD14, ЛПС-связывающего белка (LBS), а также антител (AT) IgA к ЭТ с уровнем острофазных белков (СРБ) и цитокинов (IL-6) в крови больных шизофренией $[8,9]$.

Известно, что главными клетками крови, акцептирующими ЛПС, являются полиморфноядерные лейкоциты (ПЯЛ) [10]. При дегрануляции в очаге воспаления активированные ПЯЛ выбрасывают лейкоцитарную эластазу - фермент азурофильных гранул из группы сериновых протеаз, играющую важную роль в увеличении проницаемости сосудистой стенки. Под действием различных факторов, включая IL-6, в ходе развития воспаления наблюдается повышение активности острофазного белка $\alpha 1-П И$, синтезируемого в печени и являющегося основным ингибитором ЛЭ. В наших предыдущих исследованиях было неоднократно показано, что активность ЛЭ и $\alpha 1$ ПИ связана с остротой шизофренического процесса. В качестве маркера тяжести патологического процесса в головном мозге может выступать высокий уровень АТ к нейроантигенам в сыворотке крови $[11,12]$.

\section{ЦЕЛЬ ИССЛЕДОВАНИЯ}

Анализ сопряженности процессов системного воспаления и СЭЕ во взаимосвязи с клиническими особенностями пациентов с эндогенными психозами до и после психофармакотерапии.

\section{МАТЕРИАЛЫ И МЕТОДЫ}

Исследование выполнено на базе подразделений ФГБНУ НЦПЗ: в лаборатории нейроиммунологии (руководитель - профессор Т.П. Клюшник), в отделе по изучению эндогенных психических расстройств и аффективных состояний (руководитель - д.м.н. А.Н. Бархатова) совместно с сотрудниками лаборатории системной эндотоксинемии и шока ФГБНУ НИИОПП (руководитель профессор М.Ю. Яковлев).

Клинико-иммунологическое обследование выполнено на 25 пациентах женского пола в возрасте от 23 до 49 лет с параноидной шизофренией (F20.00, F20.01 по МКБ-10) и шизоаффективным психозом (F25.0), развивающимися в рамках приступообразного течения заболевания (основная группа). Средний возраст обследованных, госпитализированных в клинику ФГБНУ НЦПЗ в связи с обострением психопатологической симптомати-

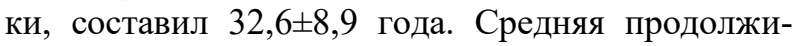
тельность лечения - 1,6 $\pm 0,5$ месяца. Во время пребывания в клинике все пациенты находились на традиционной антипсихотической терапии в соответствии с клиническими показаниями.

Оценка психического состояния пациентов осуществлялась методом клинического наблюдения и психометрическим методом с использованием унифицированной международной шкалы оценки позитивных и негативных синдромов (PANSS).

Контрольная группа состояла из 25 психически и соматически здоровых женщин, сопоставимых по возрасту с пациентами основной группы. Средний возраст обследованных в контрольной группе составил 32,2 $\pm 9,4$ года.

Обследование пациентов проводилось при поступлении в стационар (в остром психотическом состоянии) и перед выпиской из стационара (после проведенной фармакотерапии).

Критерии включения: 1) наличие у обследуемых острого психотического состояния в рамках шизофрении или шизоаффективного психоза, что приводило к необходимости госпитализации пациентов в стационар и проведения курса фармакотерапии; 2) добровольное информированное согласие на участие в исследовании.

Критерии невключения: 1) наличие признаков органического заболевания ЦНС, хронических соматических заболеваний в стадии декомпенсации; 2) признаки злоупотребления ПАВ; 3) обострение инфекционных, воспалительных и аутоиммунных заболеваний в течение 2 месяцев до начала обследования.

В сыворотке крови пациентов определяли воспалительные маркеры, вовлеченные в функционирование нервной системы в норме и при патологии: энзиматическую активность лейкоцитар- 
ной эластазы (ЛЭ) (нмоль/мин·мл) и функциональную активность $(\alpha 1-П И)$ (ИЕ/мл) - спектрофотометрическим методом, уровень антител (АТ) к нейроантигенам S100B и ОБМ (AT-S100B и ATОБМ) (у.е.о.п.) - методом твердофазного иммуноферментного анализа в модификации [13].

В качестве показателей СЭЕ оценивали следующие: концентрацию ЭТ в плазме крови с использованием авторского метода «Микро-ЛАЛтест» $(\mathrm{EU} / \mathrm{ml})[14,15]$, уровень АТ к гидрофобной (АТ-ЛПС-ФОБ) и гидрофильной (АТ-ЛПС-ФИЛ) частям молекулы ЛПС, а также их соотношение (АТ-ЛПС-ФИЛ/АТ-ЛПС-ФОБ) в сыворотке крови - методом «СОИС-ИФА» (у.е.о.п.) [16, 17].

Статистическая обработка полученных данных проводилась с использованием программы IBM SPSS Statistics 23. Проверка на нормальность распределения оценивалась методом Шапиро-Уилка. Полученные данные были проанализированы с помощью непараметрических статистических методов. Результаты представлены в виде медианы и интерквартильного размаха - Me (IQR). Сравнение групп по количественному признаку проводили с помощью непараметрического кри- терия Манна-Уитни (U). Корреляционный анализ выполнен методом непараметрической ранговой корреляции по Спирмену ( $\rho)$. Сопряженность между показателями оценивали при помощи критерия Пирсона $\left(\chi^{2}\right)$ и точного критерия Фишера (F). В качестве метода, используемого для выделения групп в структуре исследуемой выборки, применялся кластерный анализ.

\section{РЕЗУЛЬТАТЫ И ОБСУЖДЕНИЕ}

При обследовании пациентов в остром психотическом состоянии (до лечения) психометрическая оценка по шкале PANSS составила: по позитивной субшкале - 28 (22-31) баллов, негативной субшкале - 22 (19-23) балла, субшкале общей психопатологии - 48 (43-52) баллов. Суммарный балл PANSS был равен 97 (88-107) баллов и соответствовал критериям острого психотического эпизода. Результаты определения маркеров системного воспаления и интегральных показателей СЭИ в крови обследованных, приведенные в таблице 1 , свидетельствуют о статистически значи-

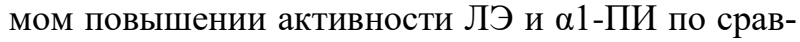
нению с контрольной группой ( $p<0,001$ и $p<0,001$ соответственно).

\section{Т а б л и ц а 1. Значения маркеров воспаления и системной эндотоксинемии} в основной и контрольной группах до психофармакотерапии - Me (IQR)

\begin{tabular}{|c|c|c|c|c|}
\hline \multicolumn{2}{|r|}{ Показатель } & $\begin{array}{c}\text { Контрольная } \\
\text { группа }(\mathrm{n}=25)\end{array}$ & $\begin{array}{c}\text { Основная } \\
\text { группа }(\mathrm{n}=25)\end{array}$ & \begin{tabular}{|} 
Уровень досто- \\
верности (p)
\end{tabular} \\
\hline \multirow{4}{*}{$\begin{array}{l}\text { Маркеры систем- } \\
\text { ного воспаления }\end{array}$} & Активность ЛЭ, нмоль/мин·мЛ & $209,7(195,2-216)$ & $264,6(248,5-272,2)$ & $\mathrm{p}<0,001 *$ \\
\hline & Активность $\alpha 1-П И$, ИЕ/мЛ & $31,5(29,0-33,3)$ & $48,5(39,7-51,2)$ & $\mathrm{p}<0,001 *$ \\
\hline & AT-S100B, у.е.о.п. & $0,74(0,63-0,78)$ & $0,72(0,62-0,9)$ & $\mathrm{p}=0,60$ \\
\hline & АТ-ОБМ, у.е.о.п. & $0,74(0,66-0,81)$ & $0,77(0,6-1,0)$ & $\mathrm{p}=0,525$ \\
\hline \multirow{4}{*}{$\begin{array}{c}\text { Показатели } \\
\text { системной } \\
\text { эндотоксинемии }\end{array}$} & АТ-ЛПС-ФОБ, у.е.о.п. & $202(192,5-210,5)$ & $172,5(117,5-236)$ & $\mathrm{p}=0,449$ \\
\hline & АТ-ЛПС-ФИЛ, у.е.о.п. & $399(389-409)$ & $353(248-525,5)$ & $\mathrm{p}=0,618$ \\
\hline & ЭТ, ЕU/мЛ & $0,45(0,3-0,75)$ & $0,6(0,3-1,05)$ & $\mathrm{p}=0,270$ \\
\hline & $\begin{array}{l}\text { Отношение } \\
\text { АТ-ЛПС-ФИЛ/АТ-ЛПС-ФОБ }\end{array}$ & $1,96(1,9-2,1)$ & $2,2(1,2-3,8)$ & $\mathrm{p}=0,449$ \\
\hline
\end{tabular}

П р и м е ч а н и е. Статистические значимые различия с контрольной группой: * - p<0,001.

Медиана уровня АТ к S100B и ОБМ, а также показателей СЭЕ не отличалась от значений контрольной группы (p>0,05). Вместе с тем наблюдалась значительная вариабельность этих показателей; были выявлены значения, выходящие в обе стороны за пределы диапазона контроля. Доля пациентов с низким уровнем АТ-ЛПС-ФОБ составила $64 \%$, а доля больных с низким уровнем АТ-ЛПС-ФИЛ - 52\%. В свою очередь активация АЭИ выявлена в 28\% и $36 \%$ случаев соответственно. Наибольший разброс показателей был характерен для АТ-ЛПС-ФИЛ - от 157 до 1064 у.е.о.п.

При анализе клинико-биологических взаимосвязей выявлены статистически значимые прямые корреляции умеренной силы $(0,3 \leq \rho \leq 0,7)$ между активностью ЛЭ и баллом по субшкале общей психопатологии PANSS ( $\rho=0,44, p=0,0402)$; уровнем АТ к S100B, концентрацией ЭТ, уровнем АTЛПС-ФИЛ и баллом по позитивной субшкале $(\rho=0,699, \quad p=0,0001 ; \rho=0,387, \quad p=0,043 ; \rho=0,347$, $\mathrm{p}=0,04$ соответственно). Кроме того, обнаружены связи между уровнем АТ-ЛПС-ФОБ и баллом по негативной субшкале $(\rho=0,476, p=0,04)$ и субшкале общей психопатологии PANSS $(\rho=0,441$, $\mathrm{p}=0,02)$. Выявленные клинико-биологические взаимосвязи подтверждают вовлеченность анализируемых показателей воспаления и СЭЕ в патогенез эндогенных психозов.

В таблице 2 показаны результаты анализа сопряженности анализируемых отклонений иммунной системы и СЭЕ. 
Т а б л и ц а 2. Корреляционные связи между маркерами системного воспаления и показателями системной эндотоксинемии у пациентов с эндогенными психозами до психофармакотерапии

\begin{tabular}{|l|c|c|}
\multicolumn{1}{|c|}{ Показатель } & $\begin{array}{c}\text { Коэффициент корреля- } \\
\text { ции Спирмена ( } \rho)\end{array}$ & $\begin{array}{c}\text { Уровень } \\
\text { достоверности (p) }\end{array}$ \\
\hline AT-S100B vs. ЭТ & 0,323 & $\mathrm{p}=0,042^{*}$ \\
\hline AТ-ОБМ vs. ЭТ & 0,348 & $\mathrm{p}=0,047^{*}$ \\
\hline AT-S100 В vs. АТ-ЛПС-ФИЛ & 0,572 & $\mathrm{p}=0,004^{*}$ \\
\hline AT-S100В vs. Отношение АТ-ЛПС-ФИЛ/АТ-ЛПС-ФОБ & 0,443 & $\mathrm{p}=0,003^{*}$ \\
\hline
\end{tabular}

П р и м е ч а н и е. Статистические значимые различия между показателями связи: * $-\mathrm{p}<0,05$;

$0,3 \leq \rho \leq 0,7-$ умеренная теснота корреляционной связи.

Приведённые в таблице 2 результаты свидетельствуют, что увеличение уровня АТ к нейроантигенам (преимущественно к белку S100B) коррелирует с повышением концентрации ЭТ и АТ-ЛПС-ФИЛ. В связи с тем, что наличие аутоиммунного компонента к нейроантигенам характеризует наиболее тяжелые варианты течения психозов $[18,19]$, выявленные корреляции могут отражать роль СЭЕ в модификации иммунного ответа при утяжелении психопатологической симптоматики пациентов $[20,21]$.

При повторном клинико-биологическом обследовании, проведенном после психофармакотерапии, в основной группе пациентов наблюдалось выраженное улучшение их клинического состояния, что подтверждается редукцией баллов по PANSS. Статистически значимое снижение балльной оценки выявлено по всем субшкалам PANSS: позитивной субшкале - 13 (11-15) баллов $(\mathrm{p}=0,000028)$, негативной субшкале - $18(16-20)$ баллов $(\mathrm{p}<0,001)$ и субшкале общих психопатоло- гических симптомов - 30 (29-34) баллов $(\mathrm{p}=0,000018)$. Суммарный балл PANSS также снизился, составив 62 (56-70) балла ( $\mathrm{p}=0,000012)$.

Однако, несмотря на выраженное улучшение клинико-психопатологической симптоматики, оцененной по психометрической шкале PANSS, при анализе показателей иммунной системы и СЭЕ относительная нормализация была обнаружена лишь для активности ЛЭ $(\mathrm{p}=0,011)$. Вместе с тем медиана показателя оставалась выше, чем в контрольной группе - 240,8 $(230,0-263,4)$ нмоль/мин 'мл ( $\mathrm{p}=0,00026)$. Полученные результаты, предположительно, отражают пролонгирующее течение патологического процесса в головном мозге пациентов.

Результаты определения исследуемых показателей в основной группе пациентов с эндогенными психозами до и после проведенной терапии, представленные в процентах относительно контрольных значений, приведены на рисунке 1.

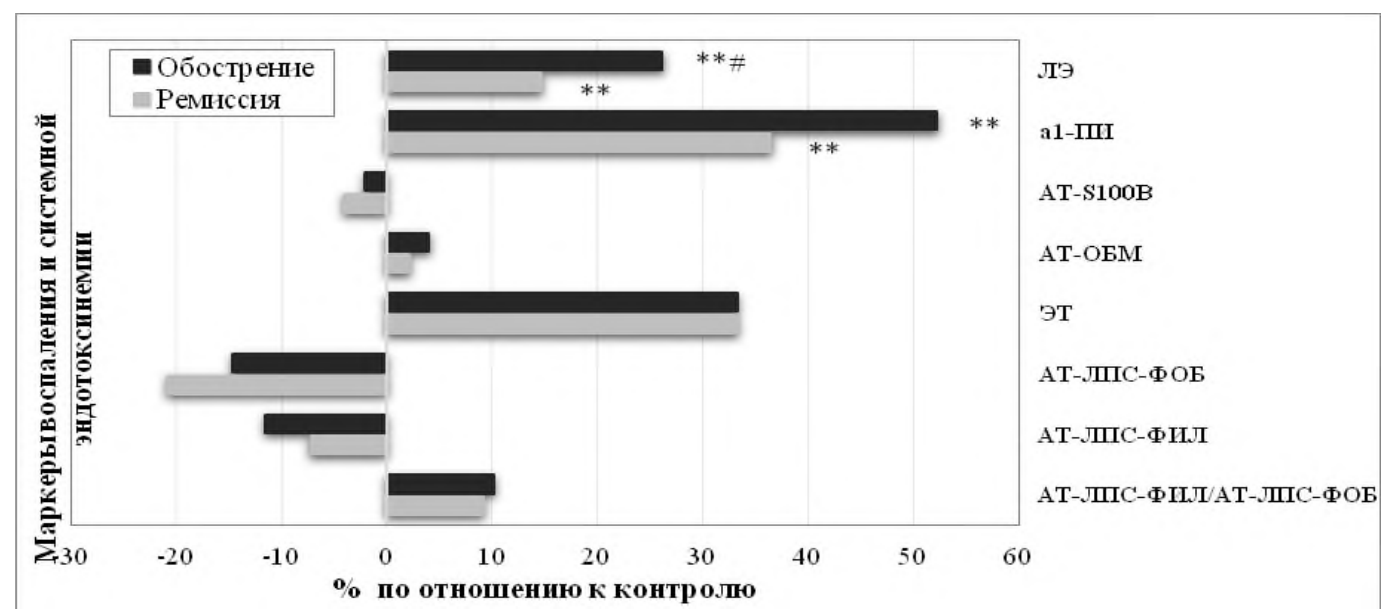

Р и с у н о к 1 . Значения маркеров воспаления и системной эндотоксинемии в основной и контрольной группах до и после психофармакотерапии

П р и м е ч а н и е. Статистические значимые различия с контролем: ** - p $<0,001$; статистические значимые различия показателей до и после проведенной фармакотерапии: \# - p<0,05.

Несмотря на отсутствие статистически значимых различий большинства анализируемых биологических показателей в основной группе пациентов до и после лечения, детальный анализ вы- явил различную динамику этих показателей, что, вероятно, свидетельствует о различной эффективности проведенной терапии у пациентов на момент их повторного обследования. 
Данное наблюдение послужило основанием для последующего выполнения кластерного анализа, с использованием которого в структуре выборки пациентов было выделено два кластера. В качестве кластеризующих признаков нами были использованы маркеры системного воспаления (активность ЛЭ, функциональная активность $\alpha 1$ ПИ и уровень АТ к нейроантигенам S100B и ОБМ), это объясняется тем, что, как было показано ранее, их уровень напрямую связан с тяжестью и активностью патологического процесса в головном мозге $[11,12]$. Осуществленный двухэтапный кластерный анализ показал, что доля первого кластера в общей совокупности составила 56,0\% (14 человек), доля второго кластера $44,0 \%$ (11 человек). Отношение наибольшего кластера к наименьшему составило 1,27 . Силуэтная мера связности и разделения кластеров составила 0,5 .

В таблице 3 рассматриваются результаты сравнения выделенных кластеров по значениям кластеризующих переменных.

Т а б л и ц а 3. Сравнение первого и второго кластеров по значениям связанных воспалительных маркеров в основной и контрольной группах после психофармакотерапии

\begin{tabular}{|c|c|c|c|c|c|c|c|}
\hline \multirow{3}{*}{ Показатель } & \multirow{2}{*}{\multicolumn{2}{|c|}{$\begin{array}{c}\text { Контрольная } \\
\text { группа }(\mathrm{n}=15)\end{array}$}} & \multicolumn{4}{|c|}{ Основная группа $(n=25)$} & \multirow{3}{*}{$\mathrm{p}_{1-2}$} \\
\hline & & & \multicolumn{2}{|c|}{ Первый кластер (n=14) } & \multicolumn{2}{|c|}{ Второй кластер $(\mathrm{n}=11)$} & \\
\hline & $\mathrm{Me}$ & IQR & $\mathrm{Me}$ & IQR & $\mathrm{Me}$ & IQR & \\
\hline \begin{tabular}{|c|} 
Активность ЛЭ, \\
нмоль/мин·мЛ
\end{tabular} & 209,7 & $\begin{array}{l}195,2- \\
216,0\end{array}$ & $\begin{array}{c}235,4 \\
\mathrm{p}_{\text {контр }}=0,041 *\end{array}$ & $200,8-244,2$ & $\begin{array}{c}259,2 \\
\mathrm{p}_{\text {контр }}<0,001 * *\end{array}$ & $244,0-270,8$ & 0,051 \\
\hline $\begin{array}{c}\text { Активность } \alpha 1- \\
П И, \text { ИЕ/мЛ }\end{array}$ & 31,5 & $29,0-33,3$ & $\begin{array}{c}38,2 \\
\mathrm{p}_{\text {контр }}=0,009 *\end{array}$ & $32,7-48,0$ & $\begin{array}{c}42,0 \\
\mathrm{p}_{\text {контр }}<0,001 * *\end{array}$ & $40,6-44,2$ & 0,809 \\
\hline $\begin{array}{c}\text { AT-S100B, } \\
\text { у.е.о.п. }\end{array}$ & 0,74 & $0,63-0,78$ & $\begin{array}{c}0,65 \\
\mathrm{p}_{\text {контр }}=0,047 *\end{array}$ & $0,61-0,67$ & $\begin{array}{c}0,88 \\
\mathrm{p}_{\text {контр }}<0,001 *\end{array}$ & $0,80-0,91$ & $<0,0010$ \\
\hline $\begin{array}{l}\text { АТ-ОБМ, } \\
\text { у.е.о.п. }\end{array}$ & 0,74 & $0,66-0,81$ & $\begin{array}{c}0,64 \\
\mathrm{p}_{\text {контр }}=0,046^{*}\end{array}$ & $0,58-0,72$ & $\begin{array}{c}0,93 \\
\mathrm{p}_{\text {контр }}<0,001 * *\end{array}$ & $0,88-1,04$ & $<0,0010$ \\
\hline
\end{tabular}

П р и м е ч а н и е. Статистически значимые различия с контрольной группой: * $-\mathrm{p}<0,05 ; * *-\mathrm{p}<0,001$; между выделенными кластерами различия: $\mathbb{a}-\mathrm{p}<0,001$.

Наибольшие различия между кластерами у пациентов основной группы отмечены в отношении активности ЛЭ ( $\mathrm{p}=0,051$ на уровне тенденции) и уровня АТ к нейроантигенам ( $<0,001)$. Для пациентов первого кластера характерен относительно низкий уровень активации иммунной системы: умеренное повышение энзиматической активности ЛЭ и функциональной активности $\alpha 1-П И$, сопровождающееся сниженным уровнем антител к белкам S100B и ОБМ $(\mathrm{p}<0,05)$ по сравнению с контрольной группой, что отражает положительную динамику анализируемых воспалительных маркеров после курса психофармакотерапии.

Напротив, пациенты, вошедшие во второй кластер, характеризовались высоким уровнем ак- тивации иммунной системы, сопровождающимся выраженным повышением активности как ЛЭ, так и $\alpha 1-П И$, а также активацией аутоиммунных реакций к обоим исследуемым антигенам, что отражает продолжающееся активное течение патологического процесса в головном мозге, несмотря на проведенную психофармакотерапию. Вероятно, улучшение клинико-психопатологического состояния пациентов основной группы по всем субшкалам PANSS соответствует терапевтической (нестабильной) ремиссии низкого качества.

В выделенных «иммунологических» кластерах были проанализированы интегральные показатели СЭЕ. Результаты, полученные в ходе проведенного анализа, приведены в таблице 4.

Таблица 4. Сравнение первого и второго кластеров по значениям системной эндотоксинемии в основной и контрольной группах после психофармакотерапии

\begin{tabular}{|c|c|c|c|c|c|c|c|}
\hline \multirow[t]{3}{*}{ Показатель } & \multirow{2}{*}{\multicolumn{2}{|c|}{$\begin{array}{c}\text { Контрольная группа } \\
(\mathrm{n}=15)\end{array}$}} & \multicolumn{4}{|c|}{ Основная группа $(\mathrm{n}=25)$} & \multirow{3}{*}{$\mathrm{p}_{1-2}$} \\
\hline & & & \multicolumn{2}{|c|}{ Первый кластер (n=14) } & \multicolumn{2}{|c|}{ Второй кластер $(\mathrm{n}=11)$} & \\
\hline & $\mathrm{Me}$ & IQR & $\mathrm{Me}$ & IQR & $\mathrm{Me}$ & IQR & \\
\hline $\begin{array}{l}\text { АТ-ФОБ, } \\
\text { у.е.о.п. }\end{array}$ & 202,0 & $192,5-210,5$ & $\begin{array}{c}188,0 \\
\mathrm{p}_{\text {контр }}=0,747\end{array}$ & $152,0-320,0$ & $\begin{array}{c}153,0 \\
\mathrm{p}_{\text {контр }}=0,004 *\end{array}$ & $110,0-175,0$ & 0,202 \\
\hline $\begin{array}{l}\text { АТ-ФИЛ, } \\
\text { у.е.о.п. }\end{array}$ & 399,0 & $389,0-409,0$ & $\begin{array}{c}443,5 \\
\mathrm{p}_{\text {контр }}=0,172\end{array}$ & $374,0-505,0$ & $\begin{array}{c}364,0 \\
\mathrm{p}_{\text {контр }}=0,217\end{array}$ & $313,5-495,5$ & 0,467 \\
\hline ЭТ, ЕU/мЛ & 0,45 & $0,3-0,75$ & $\begin{array}{c}0,75 \\
\mathrm{p}_{\text {контр }}=0,146\end{array}$ & $0,3-1,2$ & $\begin{array}{c}0,9 \\
\mathrm{p}_{\text {контр }}=0,001 *\end{array}$ & $0,75-1,80$ & 0,267 \\
\hline $\begin{array}{l}\text { Отношение АТ- } \\
\text { ФИЛ/АТ-ФОБ }\end{array}$ & 1,96 & $1,9-2,1$ & $\begin{array}{c}1,76 \\
\mathrm{p}_{\text {контр }}=0,533\end{array}$ & $1,19-2,87$ & $\begin{array}{c}2,18 \\
\mathrm{p}_{\text {контр }}=0,036 *\end{array}$ & $2,1-3,1$ & 0,166 \\
\hline
\end{tabular}

П р и м е ч а н и е. Статистически значимые различия с контрольной группой: $*-p<0,05 ; * *-p<0,001$. 
Показано, что у пациентов первого кластера концентрация ЭТ и антиэндотоксиновых АТ находилась в пределах диапазона значений контроля. Напротив, в крови пациентов второго кластера были выявлены характерные признаки ЭА, а именно повышенная концентрация ЛПС в плазме крови $(\mathrm{p}=0,001)$, сопровождаемая сниженным уровнем АТ-ЛПС-ФОБ $(\mathrm{p}<0,05)$ и «нормальным» уровнем АТ-ЛПС-ФИЛ $(p>0,05)$ по сравнению с контрольной группой. Коэффициент соотношения антиэндотоксиновых АТ значимо превышал контрольные показатели ( $<<0,05)$.

Диаграммы, иллюстрирующие различную динамику изучаемых маркеров системного воспаления маркеров, а также показателей СЭЕ у пациентов выделенных кластеров после психофармакотерапии представлены на рисунке 2.

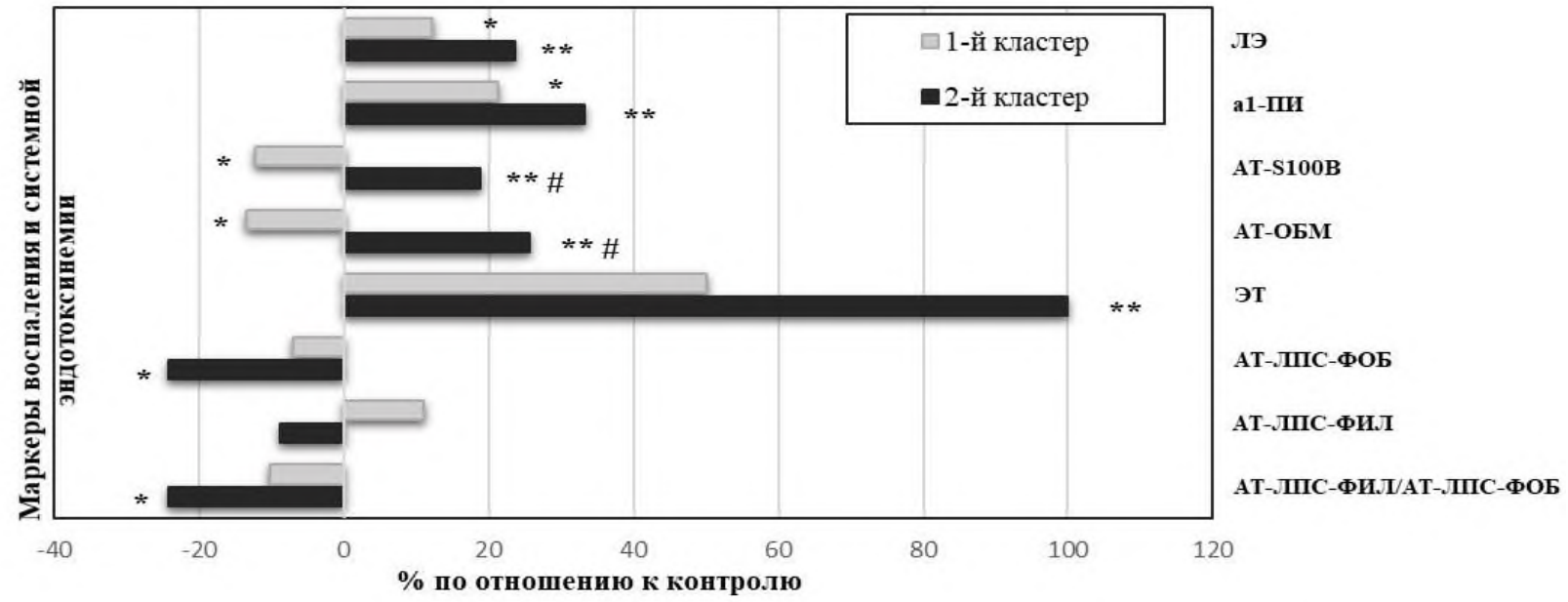

Рисунок 2. Сравнение первого и второго кластеров по значениям маркеров воспаления и системной эндотоксиненемии в основной и контрольной группах после психофармакотерапии

П р и м е ч а н и е. Статистически значимые различия с контрольной группой: * $-\mathrm{p}<0,05 ; * *-\mathrm{p}<0,001$; различия между выделенными кластерами: \# - p<0,05.

Частота встречаемости гипериммунных сывороток и образцов с высокой концентрацией ЛПС оказалась статистически значимо выше у пациен- тов, отнесенных ко второму кластеру, по сравнению с пациентами первого кластера $(\mathrm{p}<0,001)$ (табл. 5).

Т а б л и ц а 5 . Частота встречаемости образцов крови в связи с наличием высокого уровня аутоантител к нейроантигенам и повышением концентрации эндотоксина в основной группе после психофармакотерапии

\begin{tabular}{|c|c|c|c|c|c|c|c|c|}
\hline \multirow{3}{*}{ Основная группа } & \multicolumn{4}{|c|}{ Аутоантитела к нейроантигенам } & \multicolumn{4}{|c|}{ Эндотоксин } \\
\hline & \multicolumn{2}{|c|}{ Наличие фактора } & \multicolumn{2}{|c|}{ Отсутствие фактора } & \multicolumn{2}{|c|}{ Наличие фактора } & \multicolumn{2}{|c|}{ Отсутствие фактора } \\
\hline & Абс. & $\%$ & Абс. & $\%$ & Абс. & $\%$ & Абс. & $\%$ \\
\hline Первый кластер & 0 & 0,0 & 14 & 100,0 & 3 & 21,4 & 11 & 78,6 \\
\hline Второй кластер & 8 & 72,7 & 3 & 27,3 & 9 & 81,8 & 2 & 19,2 \\
\hline Уровень достоверности (p) & \multicolumn{4}{|c|}{$<0,001 *$} & \multicolumn{4}{|c|}{$0,015^{*}$} \\
\hline
\end{tabular}

П р и м е ч а н и е. Статистические значимые различия с контрольной группой: * $-\mathrm{p}<0,05$.

Методом корреляционного анализа проведено изучение взаимосвязей между биологическими показателями, входящими в каждый из выделенных кластеров. В первом кластере значимых корреляционных связей выявлено не было. Во втором кластере наблюдались связи умеренной силы между воспалительными маркерами и показателями СЭЕ. Обнаружены прямые связи между концентрацией ЛПС и уровнем АТ к ОБМ $(\rho=0,638, p=0,019)$, а также между коэффициентом соотношения антиэндотоксиновых АТ и уровнем AT к S100B $(\rho=0,556, p=0,048)$, что, предположительно, свидетельствует об участии эндотоксинового фактора если не в инициации, то, по меньшей мере, в патогенезе ЭГП.

\section{ОБСУЖДЕНИЕ РЕЗУЛЬТАТОВ}

Проведённое исследование свидетельствует о различной степени нормализации текущего патологического процесса у пациентов с ЭГП после проведенной психофармакотерапии. Более половины обследованных пациентов (56\%) отличались хорошей эффективностью терапии, совпадающей с относительной нормализацией воспалительных

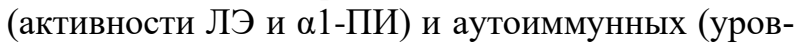
ня АТ к нейроантигеам S100B и ОБM) биомаркеров, а также интегральных показателей СЭЕ 
(концентрации ЭТ и уровня АТ к гидрофильной и гидрофобной частям его молекулы) в крови обследованных. У остальных пациентов (44\%), несмотря на улучшение клиникопсихопатологического состояния после психофармакотерапии, положительной динамики по исследуемым показателям не наблюдалось, что, вероятно, может быть следствием ЛПСиндуцированного аутоиммунного процесса, поскольку ЭТ является лигандом центрального рецептора врождённого иммунитета (TLR4), взаимодействие с которым обусловливает повышение активности адаптивного иммунитета [10].

Результаты проведенного исследования свидетельствуют о вовлеченности системного воспаления и СЭЕ в патогенез ЭГП. Развитию ЭА способствует выявленный у пациентов дефицит антиэндотоксиновых АТ к гидрофобной части молекулы (являющейся носителем практически всего спектра биологических свойств ЭТ). Сопряженность процессов системного воспаления и СЭЕ, обусловленной поступлением избыточного количества ЛПС в системный кровоток, наблюдается лишь у пациентов с активным патологическим процессом в головном мозге, что дополнительно подтверждается выявленными корреляциями между исследуемыми показателями. Анализ сопряженности изучаемых систем во взаимосвязи с клинико-психопатологическим состоянием пациентов до и после психофармакотерапии позволяет предположить возможное участие ЭА в утяжелении психопатологической симптоматики пациентов с ЭГП, а также недостаточную эффективность проводимой терапии у части обследованных пациентов. Высокая концентрация ЛПС в крови пациентов может рассматриваться в качестве эпигенетического фактора, модифицирующего течение шизофренического процесса, и дополнительной терапевтической мишени ЭПГ, в первую очередь в случае резистентных к терапии пациентов. Таким образом, участие ЭА в патогенезе ЭГП становится всё более очевидным.

Гипотеза о способности кишечного ЭТ быть одной из возможных причин индукции воспаления, выдвинутая более трети века назад [22, 23], потребовала создания новых методов исследования [24] и поиска средств снижения уровня ЭТ в крови [25], комбинация которых получила название «мультивекторная антиэндотоксиновая составляющая» (МАЭС) [26]. Она индивидуальна, состоит из энтеросорбентов, эубиотиков, желчегонных и иных лекарств и процедур, способна существенно повышать эффективность лечения многих заболеваний, таких как аллергозы, сахарный диабет, женское бесплодие, вирусные инфекции и др. $[10,26]$, и, что наиболее интересно для психиатров, нервной анорексии [27].

\section{ЗАКЛЮЧЕНИЕ}

Анализ сопряженности процессов системного воспаления и системной эндотоксинемии во взаимосвязи с клинико-психопатологическим состоянием пациентов до и после психофармакотерапии позволяет сделать предположение о возможном участии эндотоксиновой агрессии в утяжелении психопатологической симптоматики пациентов с ЭГП.

Эндотоксиновая агрессия (патогенная форма системной эндотоксинемии) кишечного происхождения, предположительно, может являться важным звеном патогенеза ЭГП и служить одним из факторов, способствующих гиперактивации врождённого иммунитета, которая лежит в основе индукции и прогрессирования аутоиммунных процессов. Невысокая эффективность психофармакотерапии в контингенте больных ЭГП, выявленная у части пациентов, предположительно, может определяться недостаточным вниманием к кишечному фактору в патогенезе психозов. Выявление эндотоксиновой агрессии у пациентов с эндогенными психозами может служить основанием для возможного дополнения к психотропным препаратам схемы лечения МАЭС, которая хорошо зарекомендовала себя в самых различных клинических отраслях практической медицины.

\section{КОНФЛИКТ ИНТЕРЕСОВ}

Представленные в настоящей статье материалы не содержат каких-либо потенциальных или явных конфликтов интересов авторов.

\section{ИСТОЧНИК ФИНАНСИРОВАНИЯ}

Исследование выполнено в рамках бюджетного финансирования темы НИР №АААА-А19119040490097-2 «Нейрохимические и нейроиммунные взаимосвязи, включая пептидную регуляцию, при эндогенных психических и нейродегенеративных заболеваниях; создание математических моделей для клинического применения».

\section{СООТВЕТСТВИЕ ПРИНЦИПАМ ЭТИКИ}

Работа соответствует этическим стандартам Хельсинской декларации ВМА (протокол заседания локального этического комитета при ФГБНУ НЦПЗ № 301 от 05.09.2016 г.).

\section{ЛИТЕРАТУРА/REFERENCES}

1. Moreno-Küstner B., Martín C., Pastor L. Prevalence of psychotic disorders and its association with methodological issues. A systematic review and meta-analyses. PLoS One 2018; 13(4): e0195687. https://doi.org/10.1371/journal.pone.0195687

2. Calafato M.R., Bramon E. The interplay between genetics, cognition and schizophrenia. Brain. 2019 February; 42(2):236-238 https://doi.org/10.1093/brain/awy345

3. Kelly J.K., Minuto C., Cryan J.F., Clarke G., Dinan T.G. The role of the gut microbiome in the development of schizophrenia. Schizophrenia Research. 
$2020 \quad$ Apr 23;S0920-9964(20)30086-4. doi: 10.1016/j.schres.2020.02.010

4. Yuan X., Kang Y., Zhuo C., Huang X.-F., Song X. The gut microbiota promotes the pathogenesis of schizophrenia via multiple pathways. Biochemical and Biophysical Research Communications. 2019; 512(2):

$373-380$ https://doi.org/10.1016/j.bbrc.2019.02.152 0006-291

5. Kelley K.W., Reaux-Le Goazigo A. Dialing in the dialogue between inflammation and the brain. Brain, Behavior, and Immunity. 2020 Aug; 88: 252-255. https://doi.org/10.1016/j.bbi.2020.01.022

6. Munford R.S. Endotoxemia - menace, marker, or mistake? J Leukoc Biol. 2016 Oct;100(4):687-698. doi: 10.1189/jlb.3RU0316-151R

7. Vargas-Caraveo A., Sayd A., Montaña J., Caso J., Madrigal J., García-Bueno B., Leza J. Toll-like receptor 4 agonist and antagonist lipopolysaccharides modify innate immune response in rat brain circumventricular organs. J Neuroinflammation. 2020 Dec; 17(1):6. https://doi:10.1186/s12974-019-1690-2

8. Severance E.G., Gressitt K.L., Stallings C.R., Origoni A.E., Khushalani S., Leweke F.M., Dickerson F.B., Yolken R.H. Discordant patterns of bacterial translocation markers and implications for innate immune imbalances in schizophrenia. Schizophr Res. 2013 Aug; 148(1-3):130-7 https://doi.org/ 10.1016/j.schres.2013.05.018

9. Delaney S., Fallon B., Alaedini A. Inflammatory biomarkers in psychosis and clinical high risk populations. Schizophr Res. 2018 Nov; 206: 44043. https://doi.org/10.1016/j.schres.2018.10.017

10. Яковлев М.Ю. Глава 8. Кишечный эндотоксин и воспаление. В книге: Дерматовенерология. Национальное руководство (краткое издание) / под ред. Ю.С. Бутова, Ю.К. Скрипкина, О.Л. Иванова. М. : ГЭОТАР-Медиа, 2013: 70-76. Үаkovlev M.Yu. Chapter 8. Intestinal endotoxin and inflammation. In the book: Dermatovenereology. National Handbook (short edition) / edited by Yu.S. Butov, Yu.K. Skripkin, O.L. Ivanov. Moscow: GEOTAR-Media, 2013: 70-76 (in Russian).

11. Клюшник Т. П., Андросова Л. В., Зозуля С.А., Отман И.Н., Никитина В.Б., Ветлугина Т.П. Сравнительный анализ воспалительных маркеров при эндогенных и непсихотических психических расстройствах. Сибирский вестник психиатрии и наркологии. 2018; 2 (99): 64-69. Klyushnik T.P., Androsova L.V., Zozulya S.A., Otman I.N., Nikitina V.B., Vetlugina T.P. Comparative analysis of inflammatory markers in endogenous and nonpsychotic mental disorders. Siberian Herald of Psychiatry and Addiction Psychiatry. 2018; 2 (99): 64-69 https://doi.org/10.26617/1810-3111-2018-2(99)64-69 (in Russian)

12. Клюшник Т.П., Зозуля С.А., Олейчик И.В. Глава 3. Маркеры активации иммунной системы в мониторинге течения эндогенных психических заболеваний. В книге: Биологические маркеры шизофрении: поиск и клиническое применение / под ред. Н.А. Бохана, С.А. Ивановой. Новосибирск: Издательство СО РАН, 2017: 34-46. Klyushnik T.P., Zozulya S.A., Oleichik I.V. Chapter 3. Markers of activation of the immune system in monitoring the course of endogenous mental illness. In the book: Biological markers of schizophrenia: search and clinical application / ed. N.A. Bokhan, S.A. Ivanova. Novosibirsk: Publishing House of SB RAS, 2017: 34-46 (in Russian).

13. Клюшник Т.П., Зозуля С.А., Андросова Л.В., Сарманова 3.В., Отман И.Н., Пантелеева Г.П., Олейчик И.В., Копейко Г.И., Борисова О.А., Абрамова Л.И., Бологов П.В., Столяров С.А. Лабораторная диагностика в мониторинге пациентов с эндогенными психозами («Нейроиммунотест»): Медицинская технология. 2-е изд., испр. и доп. М. : Медицинское информационное агентство», 2016: 32. Klyushnik T.P., Zozulya S.A., Androsova L.V., Sarmanova Z.V., Otman I.N., Panteleeva G.P., Oleichik I.V., Kopeiko G.I., Borisova O.A., Abramova L.I., Bologov P.V., Stolyarov S.A. Laboratory diagnostics in monitoring patients with endogenous psychosis ("Neuroimmune test"): Medical technology. 2nd ed., rev. and updated. Moscow: Publishing House "Medical Information Agency", 2016: 32 (in Russian).

14. Уразаев Р.А., Крупник А.Н., Яковлев М.Ю. Эндотоксинемия в раннем периоде адаптации новорожденных и их матерей. Казанский медицинский журнал.1992; 73(2):114-118. Urazaev R.A., Krupnik A.N., Yakovlev M.Yu. Endotoxinemia in early period of adaptation in infants and their mothers. Kazan Medical Journal. 1992; 73 (2): 114-118 (in Russian).

15. Зинкевич О.Д., Аниховская И.А., Сафина Н.А., Салахов И.М., Уразаев Р.А., Хабриев Р.У., Яковлев М.Ю. Способ определения активности эндотоксина (варианты). Патент на изобретение RUS 2169367 Заявл. 16.08.2000; Опубл. 20.06.2001. Zinkevich O.D., Anikhovskaya I.A., Safina N.A., Salakhov I.M., Urazaev R.A., Khabriev R.U., Yakovlev M.Yu. Method for determining endotoxin activity (options). Patent for invention RUS 2169367 Appl. on 08.16.2000; Published on June 20, 2001(in Russian).

16. Уразаев Р.А., Яковлев М.Ю., Аниховская И.А., Гатауллин Ю.К, Гатауллина Р.И., Крупник А.Н., Суджян Е.В. Способ оценки резистентности организма. Патент на изобретение RUS 2011993. Научно-инвестиционная компания "Мечников". Международный медицинский консорциум "Мечников". Заявл. 25.06.1992; Опубл. 30.07.1994 Urazaev R.A., Yakovlev M.Yu., Anikhovskaya I.A., Gataullin Yu.K., Gataullina R.I., Krupnik A.N., Sudzhyan E.V. A method for assessing the resistance of the organism. Patent for invention RUS 2011993. Scientific and Investment Company "Mechnikov". International Medical 
Consortium "Mechnikov". Appl. on 25.06.1992. Published on July 30, 1994 (in Russian).

17. Аниховская И.А., Салахов И.М., Яковлев М.Ю. Способ диагностики скрыто протекающих заболеваний на основании показателей системной эндотоксинемии. Патент на изобретение RUS 2609763. Номер заявки 2015154604. Дата регистрации 21.12.2015. Дата публикации 02.02.2017. Anikhovskaya I.A., Salakhov I.M., Yakovlev M.Yu. Method for diagnosing latent diseases based on indicators of systemic endotoxinemia. Patent for invention RUS 2609763. Application number 2015154604. Registration date 21.12.2015. Publication date 02.02.2017 (in Russian).

18. Зозуля С.А., Сизов С.В., Олейчик И.В., Клюшник Т.П. Клинико-психопатологические и иммунологические особенности маниакальнобредовых (в том числе маниакальнопарафренных) состояний, протекающих с бредом величия. Социальная и клиническая психиатрия. 2019;29(4):5-13. Zozulya S.A., Sizov S.V., Oleichik I.V., Klyushnik T.P. Clinicalpsychopathological and immunological parameters of manic-delusional (including manic-paraphrenic) states with delusion of grandeur. Social and Clinical Psychiatry. 2019;29(4):5-13 (in Russian).

19. Захарова Н.В., Зозуля С.А., Сарманова З.В., Бравве Л.В., Отман И.Н., Клюшник Т.П. Особенности иммунного профиля больных шизофренией с кататоническим синдромом. Журнал неврологии и психиатрии им. С.С. Корсакова. 2020; 120(5; 2):46-53. Zakharova N.V., Zozulya S.A., Sarmanova Z.V., Bravve L.V., Otman I.N., Klyushnik T.P. Features of the immune profile of schizophrenic patients with catatonic syndrome. S.S. Korsakov Journal of Neurology and Psychiatry. 2020; 120(5;2):46-53 https://doi.org/10.17116/jnevro202012005246 (in Russian).

20. Moreno-Küstner B., Mayoral F., Rivas F., Angona P., Requena J., García-Herrera J.M., Navas D., Moreno P., Serrano-Blanco A., Bellón J.A. Factors associated with use of community mental health services by schizophrenia patients using multilevel analysis. BMC Health Serv Res. 2011 Oct 7;11:257. doi: 10.1186/1472-6963-11-257

21. Яковлев М.Ю. Роль кишечной микрофлоры и недостаточность барьерной функции печени в развитии эндотоксинемии и воспаления. Казанский медицинский журнал. 1988; 69(5):353-358. Yakovlev M.Yu. The role of intestinal microflora and the liver barrier disfunction in the development of endotoxinemia and inflammation. Kazan Medical Journal. 1988; 69 (5): 353-358 (in Russian).

22. Аниховская И.А., Белоглазов В.А., Гордиенко А.И., Иванов Ю.Д., Кубышкин А.В., Маркелова М.М., Покусаева Д.П., Яковлев М.Ю. Краткая история изучения роли кишечного фактора в старении и/или индукции системного воспаления: достижения, проблемы, перспективы. Патогенез. 2019; 17(1): 4-17. Anikhovskaya I.A., Beloglazov V.A., Gordienko A.I., Ivanov Yu.D., Kubyshkin A.V., Markelova M.M., Pokusaeva D.P., Yakovlev M.Yu. The brief history of the study of the role of intestinal factor in aging and/or induction of systemic inflammation: achievements, problems, prospects. Pathogenesis. 2019; 17 (1): 417 https://doi.org/10.25557/2310-0435.2019.01.417 (in Russian).

23. Аниховская И.А., Кубатиев А.А., Майский И.А., Маркелова М.М., Салахов И.М., Яковлев М.Ю. Направления поиска средств снижения концентрации эндотоксина в общей гемоциркуляции. Патогенез. 2014; 12(4): 25-30. Anikhovskaya I.A., Kubatiev A.A., Maisky I.A., Markelova M.M., Salakhov I.M., Yakovlev M.Yu. The search directions of means for reduction of endotoxin concentration in the general hemocirculation. Pathogenesis. 2014; 12(4): 25-30 (in Russian).

24. Яковлев М.Ю. Воспоминания о лучшем или об истоках эндотоксиновой теории. Актуальные проблемы общей патологии: Сборник трудов юбилейной научно-практической конференции, посвящённой 150-летию кафедры патологической анатомии / под ред. С.В. Петрова. Казань : ИД «МеДДоК», 2015: 68-80 Yakovlev M.Yu. Memories of the best or the origins of endotoxin theory. Relevant problems of general pathology: Proceedings of the jubilee scientific and practical conference dedicated to the 150th anniversary of the Department of Pathological Anatomy / ed. S.V. Petrov. Kazan: Publishing House "MedDoK", 2015: 68-80 (in Russian).

25. Chernikhova E.A., Anikhovskaya I.A., Gataullin Yu.K., Zakirova D.Z., Ivanov V.B., Savel'ev A.A., Yakovlev M.Yu. Enterosorption as an approach to the elimination of chronic endotoxin aggression. Human Physiology. 2007; 33(3): 373-374. https://doi.org/10.1134/s0362119707030164

26. Anikhovskaya I.A., Kubatiev A.A., Yakovlev M.Yu. Endotoxin theory of atherosclerosis. Human Physiology. 2015; 41(1): 89-97. https://doi.org/ $10.1134 / \mathrm{S} 036211971501002827$

27. Anikhovskaya I.A., Vyshegurov Ya.Kh., Usov I.A., Rascheskov A.Yu. Bifidobacteria as a means of prevention or treatment of endotoxin aggression in patients with chronic diseases during remission or exacerbation. Human Physiology. 2004; 30(6): 732733 https://doi.org/ 10.1023/b:hump.0000049597.09577.22

Поступила в редакцию 6.05.2020 Утверждена к печати 02.09.2020 
Зозуля Светлана Александровна, кандидат биологических наук, ведущий научный сотрудник лаборатории нейроиммунологии ФГБНУ «Научный центр психического здоровья». ORCID iD 0000-0001-5390-6007. Researcher ID J-7301-2016. Scopus Author ID 57189596252. e-mail: s.ermakova@mail.ru

Отман Ирина Николаевна, кандидат биологических наук, научный сотрудник лаборатории нейроиммунологии ФГБНУ «Научный центр психического здоровья». ORCID iD 0000-0003-3745-8413. Researcher ID G-9628-2017. e-mail: irinaot@mail.ru

Олейчик Игорь Валентинович, профессор, доктор медицинских наук, главный научный сотрудник отдела по изучению эндогенных психических расстройств и аффективных состояний ФГБНУ «Научный центр психического здоровья». ORCID iD 0000-0002-8344-0620. Researcher ID K-9462-2013. Scopus Author ID 6603601287. e-mail: i.oleichik@mail.ru

Аниховская Ирина Альфредовна, кандидат медицинских наук, ведущий научный сотрудник лаборатории системной эндотоксинемии и шока ФГБНУ «Научно-исследовательский институт общей патологии и патофизиологии»; главный врач ООО «Клинико-диагностическое общество». ORCID iD 0000-0002-9381-4948.

e-mail: 612-05-64@gmail.com

Яковлев Михаил Юрьевич, доктор медицинских наук, заведующий лабораторией системной эндотоксинемии и шока ФГБНУ «Научно-исследовательский институт общей патологии и патофизиологии»; Научный руководитель ООО «Клинико-диагностическое общество»; профессор кафедры патологической анатомии педиатрического факультета ФГБОУ ВО «Российский национальный исследовательский медицинский университет имени Н.И. Пирогова» МЗ РФ. ORCID iD 0000-0002-7166-9372. e-mail: yakovlev-lps@yandex.ru

Клюшник Татьяна Павловна, профессор, доктор медицинских наук, руководитель лаборатории нейроиммунологии ФГБНУ «Научный центр психического здоровья». ORCID iD 0000-0001-5148-3864. Researcher ID B8012-2016. e-mail: klushnik2004@mail.ru

Зозуля Светлана Александровна, s.ermakova@mail.ru

UDC 616.89-02-036:616-002.2:612.017

For citation: Zozulya S.A., Otman I.N., Oleichik I.V., Anikhovskaya I.A., Yakovlev M.Yu., Klyushnik T.P. Conjugacy between processes of systemic inflammation and systemic endotoxinemia in endogenous psychoses. Siberian Herald of Psychiatry and Addiction Psychiatry. 2020; 3 (108): 17-27. https://doi.org/10.26617/1810-3111-2020-3(108)$17-27$

\section{Conjugacy between processes of systemic inflammation and systemic endotoxinemia in endogenous psychoses \\ Zozulya S.A. ${ }^{1}$, Otman I.N. ${ }^{1}$, Oleichik I.V.', Anikhovskaya I.A. ${ }^{2,3}$, Yakovlev M.Yu. ${ }^{2,3,4}$, Klyushnik T.P. ${ }^{1}$}

${ }^{1}$ Mental Health Scientific Center

Kashirskoye Highway 34, 115522, Moscow, Russian Federation

${ }^{2}$ Research Institute of General Pathology and Pathophysiology

Baltiyskaya Street 8, 125315, Moscow, Russian Federation

${ }^{3}$ Clinical Diagnostic Society, Ltd

Nizhnyaya Maslovka Street 19, 127083, Moscow, Russian Federation

${ }^{4}$ N.I. Pirogov Russian National Research Medical University

Ostrovityanov Street 1, 117997, Moscow, Russian Federation

\section{ABSTRACT}

Objective of the study: to analyze the conjugacy of processes of systemic inflammation and systemic endotoxinemia in relation to the clinical characteristics of patients with endogenous psychoses (EGP) before and after psychopharmacotherapy. Material and Methods: the study includes 25 patients with schizophrenia (F20.0 (0-1) according to ICD-10) and schizoaffective psychosis (F25.0), examined at admission to the hospital (in an acute psychotic state) and before discharge (after performed pharmacotherapy). The control group consists of 25 healthy persons. 
Markers of systemic inflammation (activity of leukocyte elastase (LE), functional activity of $\alpha 1$-proteinase inhibitor ( $\alpha 1-\mathrm{PI})$, level of antibodies (AB) to S100B and MBP), as well as parameters of systemic endotoxinemia (SET) (endotoxin concentration, level and the ratio of antiendotoxin antibodies) in blood are determined. Results: in an acute psychotic state (at baseline), an increase in the activity of LE and $\alpha 1$-PI is revealed in the group of patients in comparison with the control group ( $\mathrm{p}<0.001)$. The level of AB to S100B and MBP, as well as the SET parameters do not differ from the control values $(p>0.05)$, however, their significant variability is observed. During the examination after the therapy, two clusters are identified in the sample structure. Markers of systemic inflammation, the level of which is associated with the activity of the pathological process in the brain, are used as clustering signs. Patients of the first cluster $(56 \%)$ have a good clinical effect and relative normalization of all parameters. In patients of the second cluster (44\%), despite an improvement in the clinical state, an increase in the activity of LE, $\alpha 1-\mathrm{PI}$, activation of autoimmune reactions to neuroantigens, as well as laboratory signs of endotoxin aggression (EA) are found: high concentration of ET in the blood plasma against the background of a deficiency of antiendotoxin AB to the hydrophobic part of its molecule $(\mathrm{p}<0.01)$. Conclusion. Analysis of the conjugacy of the studied systems in relation to the clinical state of patients with EGP before and after pharmacotherapy suggests the participation of EA in the aggravation of psychopathological symptoms in this category of patients.

Keywords: endogenous psychoses, inflammation markers, systemic endotoxinemia, autoantibodies to neuroantigens, endotoxin aggression.

Received May 06.2020

Accepted September 02.2020

Zozulya Svetlana A., PhD, lead researcher of the Laboratory of Neuroimmunology of Mental Health Scientific Center, Moscow, Russian Federation. ORCID iD 0000-0001-5390-6007. Researcher ID J-7301-2016. Scopus Author ID 57189596252.e-mail: s.ermakova@mail.ru

Otman Irina N., PhD, researcher, Laboratory of Neuroimmunology, Mental Health Scientific Center. ORCID iD 0000-0003-3745-8413. Researcher ID G-9628-2017. e-mail: irinaot@mail.ru

Oleichik Igor V., Prof., MD, chief researcher of the Department for the Study of Endogenous Mental Disorders and Affective States of Mental Health Scientific Center, Moscow, Russian Federation. ORCID iD 0000-0002-8344-0620. Researcher ID K-9462-2013. Scopus Author ID 6603601287. e-mail: i.oleichik@ mail.ru

Anikhovskaya Irina A., PhD, lead researcher, Laboratory of Systemic Endotoxinemia and Shock, Research Institute of General Pathology and Pathophysiology; chief physician of Clinical Diagnostic Society, Ltd. ORCID iD 00000002-9381-4948. e-mail: 612-05-64@gmail.com

Yakovlev Mikhail Yu., MD, Head of the Laboratory of Systemic Endotoxinemia and Shock, Research Institute of General Pathology and Pathophysiology; Scientific Supervisor of the Clinical Diagnostic Society, Ltd, Moscow, Ru ssian Federation; professor of the Department of Pathological Anatomy of the Pediatric Faculty of the N.I. Pirogov Russian National Research Medical University, Moscow, Russian Federation. ORCID iD 0000-0002-7166-9372. e-mail: yakovlev-lps@yandex.ru

Klyushnik Tatyana P., Prof., MD, Head of the Laboratory of Neuroimmunology, Mental Health Scientific Center, Moscow, Russian Federation. ORCID iD 0000-0001-5148-3864. Researcher ID B-8012-2016.

e-mail: klushnik2004@mail.ru

\section{Zozulya Svetlana A., s.ermakova@mail.ru}

